\title{
Prevalence of Abnormal Papanicolaou Test Results and Related Factors among Women Living in Zanjan, Iran
}

\author{
Azam Maleki', Elahe Ahmadnia ${ }^{1 *}$, Azar Avazeh ${ }^{2}$, Saeideh Mazloomzadeh ${ }^{3}$, \\ Behnaz Molaei $^{4}$, Ahmad Jalilvand ${ }^{5}$
}

\begin{abstract}
Background: Currently, a comprehensive program for screening and early detection of cervical cancer does not exist in Iran. This study aimed to determine the prevalence of abnormal Papanicolaou (Pap) smears and some related factors among women living in Zanjan, Iran. Materials and Methods: This cross-sectional study was conducted in 2012 in Zanjan on 4274 married women aged 20-65 years. The study participants were selected through two-stage cluster sampling. After obtaining written consent, demographic and fertility questionnaires were completed. Samples from cervix were obtained through a standard method using the Rover CervexBrush. Evaluation and interpretation of the samples were reported using the Bethesda 2001 method. Data were statistically analyzed using chi-square and logistic regression models. Results: Most inflammatory changes in the samples were mild (37.4\%). Abnormal atypical changes in the epithelial cells were found in $4.04 \%$. The highest percentage of abnormal changes in the epithelial cells was atypical squamous cells of undetermined significance (ASCUS) (1.9\%). Abnormal results of Pap smear was significantly and independently associated with age, papillomavirus infection, and lack of awareness about Pap smear tests. Conclusions: Given the high prevalence of inflammatory and precancerous changes in this study, compared to other studies in Iran and other Muslim countries, and the effect of demographic variables and individual factors on abnormal results, increasing the awareness of women and their families regarding the risk factors for cervical cancer, preventive measures such as screening, and timely treatment seem necessary.
\end{abstract}

Keywords: Uterine cervical neoplasms - cervical intraepithelial neoplasia - Papanicolaou test - Iran

Asian Pac J Cancer Prev, 16 (16), 6935-6939

\section{Introduction}

Cervical cancer is the second most common cancer among women. It annually endangers the health of countless women around the world. Almost 493 million new cases of cervical cancer are diagnosed each year worldwide. About 274 thousand women die from this disease annually, and $83 \%$ of these cases are in developing countries. (Mehmetoglu, Sadikoglu, Ozcakir, and Bilgel, 2010) Healthy People 2020 (HP2020) cervical cancer objectives include increasing screening rates to a target of $93 \%$, reducing the incidence rate to 7.1 per 100,000 women, and reducing the death rate to 2.2 per 100,000 women (available at: http:// www.healthypeople.gov). Islamic countries, including Iran, are among low risk countries in relation to the incidence of cervical cancer. Nevertheless, due to the lack of comprehensive cervical cancer screening programs in these countries and the diagnosis of this disease at more advanced stages, cervical cancer has a high fatality rate in these countries (Khorasanizadeh et al., 2013). The duration of pre-invasive cervical cancer is long and implementation of screening and treatment of precancerous lesions in the early stages has made it a preventable problem in developed countries (Ncube, Bey, Knight, Bessler, and Jolly, 2015). As a result, in the past 50 years, a significant reduction has been observed in the incidence and mortality rate of cervical cancer in developed countries. In the United States of America, the incidence of cervical cancer has allocated the sixth solid tumor to itself. However, in developing countries, this cancer is the second most common cancer in women and the leading cause of deaths due to cancer among them (Arbyn et al., 2011; Benard et al., 2014). The risk of cervical cancer can be reduced $45 \%$ by one negative Pap smear test and $99 \%$ by 9 negative tests. Lack of regular screening increases the risk of developing the disease up to 2-6 times. (Aggarwal, 2014; McGraw and Ferrante, 2014) it is believed that infection with human papillomavirus (HPV) is the main cause of the onset, development, and progression of cervical cancer (Stanley, 2012) Other factors contributing to cervical cancer are intercourse at early ages, polygamy, smoking,

${ }^{1}$ School of Nursing and Midwifery, ${ }^{2}$ Department of Midwifery, School of Nursing and Midwifery, ${ }^{4}$ Department of Obstetrics and Gynecology, ${ }^{5}$ Department of Pathology, Zanjan University of Medical Sciences, ${ }^{3}$ Zajan Social Determinants of Health Research Center, Zanjan, Iran*For correspondence:ahmad@zums.ac.ir 
multiparity, and long-term use of oral contraceptives (Zarchi et al., 2010). The basic strategies of cervical cancer prevention are reduction of risk factors, identification of individuals at risk or in the early stages of the disease, and early diagnosis through centralized cytologic screening (Aggarwal, 2014) Centralized cytologic screening can be performed using different tools and methods. Among these tools, cervical brushes are more efficient regarding the adequacy of samples and acquiring cells from the transitional zone of the cervix compared to the wooden spatula (a commonly used tool). In the study by Whitaker et al. (2009) a statistically significant difference was observed in the number of cells and the adequacy of the samples between samples obtained by the cervical brush and the cotton swab and spatula. (Whitaker, Stamp, Young, and Greenwood, 2009)

Currently, screening programs for cervical cancer and appropriate insurance coverage for this test does not

Table 1. Demographic Reproductive Characteristic of Participants

\begin{tabular}{|c|c|c|c|c|}
\hline \multicolumn{2}{|c|}{ Variable } & \multirow{3}{*}{$\begin{array}{c}\text { frequency } \\
2130 \\
1973 \\
\end{array}$} & \multirow{3}{*}{$\begin{array}{c}\text { percent } \\
51.9 \\
48.1 \\
\end{array}$} & \multirow{3}{*}{$\frac{\text { total }}{4103}$} \\
\hline \multirow{2}{*}{ Living area } & \multirow{2}{*}{$\begin{array}{l}\text { Urban } \\
\text { rural }\end{array}$} & & & \\
\hline & & & & \\
\hline \multirow{5}{*}{ Age (year) } & $\leq 25$ & 612 & 14.5 & \multirow{5}{*}{4226} \\
\hline & $26-35$ & 1667 & 39.4 & \\
\hline & $36-45$ & 1309 & 31 & \\
\hline & $46-55$ & 541 & 12.8 & \\
\hline & $56-65$ & 97 & 2.3 & \\
\hline \multirow{2}{*}{ Occupation } & Housewife & 4006 & 94.5 & \multirow{2}{*}{4237} \\
\hline & Employed & 231 & 5.5 & \\
\hline \multirow{3}{*}{$\begin{array}{c}\text { Educational } \\
\text { level }\end{array}$} & $<$ elementary & 3262 & 78 & \multirow{3}{*}{4167} \\
\hline & $\begin{array}{c}\text { Diploma, } \\
\text { high school }\end{array}$ & 708 & 17 & \\
\hline & Academic & 197 & 4.7 & \\
\hline \multirow{3}{*}{$\begin{array}{l}\text { Monthly family } \\
\text { Income } \\
(\times 1000 \text { IRR })\end{array}$} & $\leq 300$ & 1186 & 30.4 & \multirow{3}{*}{3896} \\
\hline & $300-600$ & 2235 & 57.4 & \\
\hline & $\geq 600$ & 475 & 12.2 & \\
\hline \multirow{4}{*}{ Parity } & NO & 137 & 3.2 & \multirow{4}{*}{4232} \\
\hline & 1 & 938 & 22.2 & \\
\hline & 4-Feb & 2397 & 56.6 & \\
\hline & $\geq 5$ & 760 & 18 & \\
\hline \multirow{2}{*}{ Breast feeding } & Yes & 610 & 14.4 & \multirow{2}{*}{4227} \\
\hline & no & 3617 & 85.4 & \\
\hline \multirow{2}{*}{$\begin{array}{l}\text { Consumption } \\
\text { of combine } \\
\text { hormonal } \\
\text { contraception }\end{array}$} & Yes & 1020 & 24.3 & \multirow[b]{2}{*}{4195} \\
\hline & no & 3175 & 75.7 & \\
\hline \multirow{2}{*}{ Menopause } & Yes & 410 & 9.8 & \multirow{2}{*}{4165} \\
\hline & no & 3755 & 90.2 & \\
\hline \multirow{2}{*}{$\begin{array}{l}\text { Pap smear } \\
\text { screening } \\
\text { history }\end{array}$} & Yes & 1105 & 26.3 & \multirow{2}{*}{4205} \\
\hline & no & 3100 & 73.7 & \\
\hline \multirow{2}{*}{$\begin{array}{l}\text { Awareness of } \\
\text { pap smear test }\end{array}$} & Yes & 2543 & 61.31 & \multirow{2}{*}{4148} \\
\hline & no & 1605 & 38.7 & \\
\hline
\end{tabular}

exist in Iran. Sampling of the cervix is performed on a case by case basis in patients who refer to health centers and private clinics regarding genital diseases, problems, or complaints. Annual and regular sampling of the cervix are limited to individuals who are of high socioeconomic status (Khorasanizadeh et al., 2013). Typically, a cotton swab or a wooden spatula is used for sampling which has low sensitivity and specificity. This study aimed to determine the prevalence of abnormal results of Papanicolaou (Pap) smears, using the cervical brush, and factors associated with it in women of 20-65 years of age from Zanjan province, Iran.

\section{Materials and Methods}

This study was a cross-sectional study conducted in 2012 in Zanjan. Zanjan province is 21,773 square kilometers and has a population of 1015734 residents. It is located in Northwestern Iran and has 8 large cities and 978 villages. The study population included 20-65 year-old married women living in urban and rural areas of the province. From the study population, 5000 subjects, who had not performed Pap smear test during the past 8 weeks and had the inclusion criteria, were selected via a two-stage cluster sampling method. For accessing the study subjects, each of the cities of Zanjan province (Zanjan Soltanieh, Abhar, Khoramdareh, Tarom, Ijrood, Mahneshan, and Khodabande) were considered as a cluster, and systematic sampling method was used in each cluster. The ratio of the subjects of each mentioned province to the entire sample (5000 subjects) was calculated; Zanjan 44\%, Khodabande and Abhar each 17\%, Khoramdareh $6 \%$, Tarom 5\%, Ijrood and Mahneshan each 4\%, and Soltanieh $3 \%$. The data collection tool was a questionnaire on demographic and reproductive characteristics and information about the Pap smear test results. The sections regarding the demographic and reproductive information were conducted through interviews and completed by the midwife. After obtaining written consents from the subjects, sampling was performed by trained midwives using standard methods. For correct sampling, the cervical

Table 2. Frequency of Pap Smear Screening Results Based on the Bethesda 2001

\begin{tabular}{|c|c|c|c|}
\hline \multicolumn{2}{|c|}{ Variable } & frequency & Pe rcent \\
\hline All Organism & yes & 102 & 2.38 \\
\hline \multirow{4}{*}{$\begin{array}{c}\text { Inflamation } \\
\text { changes }\end{array}$} & Metaplasia & 172 & 4.02 \\
\cline { 2 - 4 } & Mild & 1600 & 37.45 \\
\cline { 2 - 4 } & Modrate & 1070 & 25.03 \\
\cline { 2 - 4 } & Severe & 1149 & 26.9 \\
\cline { 2 - 4 } & radation & 8 & 0.18 \\
\hline \multirow{3}{*}{\begin{tabular}{c} 
Type of \\
epithelial cell \\
\cline { 2 - 4 }
\end{tabular}} & ASCUS & 81 & 1.9 \\
\cline { 2 - 4 } & ASCH & 40 & 0.93 \\
\cline { 2 - 4 } & LSIL & 43 & 1 \\
\hline Glandular cell & AGUS & 6 & 0.14 \\
\hline TOTAL & & 4274 & 100 \\
\hline
\end{tabular}


Prevalence of Abnormal Papanicolaou Test Results and Related Factors among Women Living in Zanjan, Iran

brush was rotated 360 degrees within the cervix 2 times, and then, it was rubbed on the lam. After spreading the sample on the glass lam, it was sprayed 2 times with a fixer from a distance of $20-30 \mathrm{~cm}$. Of the 5000 prepared lam samples, 726 samples were excluded from the study due to breaking of the lam or incomplete information on the questionnaires. Reviewing and reporting of 4274 samples was conducted by an expert pathologist using the Bethesda method (2001). The significance level for all statistical tests was considered as 5\%. Data were analyzed using chi-square test to compare proportions for categorical variables and logistic regression model to evaluate the association between abnormal results of Pap smear and study variables. Analysis of the data was carried out using SPSS 17.0 (SPSS Inc., Chicago, IL, USA).

Table 3. The Relationship Between Abnormal Pap Smear Result with Demograghic and Reproductive Characteristics of Participants

\begin{tabular}{|c|c|c|c|c|c|}
\hline \multicolumn{2}{|l|}{ Variable } & $\begin{array}{c}\text { With abnormal } \\
\text { result }\end{array}$ & $\begin{array}{c}\text { Without } \\
\text { abnormal result } \\
\text { Frequency }(\%) \\
\end{array}$ & $P$ value & Odds /CI 95\% \\
\hline \multirow{5}{*}{ Age (year) } & $15-25$ & $5(3)$ & $607(15)$ & - & 1 \\
\hline & $26-35$ & $41(24.4)$ & $1626(40.1)$ & 0.1 & $3.6(1.2-7.78)$ \\
\hline & $36-45$ & $70(41.7)$ & $1239(30.5)$ & 0.0001 & $6.85(2.75-17.08)$ \\
\hline & $46-55$ & $45(26.8)$ & $496(12.2)$ & 0.0001 & $11.01(4.33-27.95)$ \\
\hline & $56-65$ & $7(4.2)$ & $90(2.2)$ & 0.0001 & $9.44(2.93-30.38)$ \\
\hline \multirow{4}{*}{ Marriage age (year) } & $9-15$ & $41(24.7)$ & $719(17.9)$ & - & 1 \\
\hline & $16-20$ & $91(54.8)$ & $2038(50.9)$ & 0.0001 & $2.58(1.83-3.71)$ \\
\hline & $21-25$ & $23(13.9)$ & $922(23)$ & 0.0001 & $3.91(2.5-6.1)$ \\
\hline & $26 \geq$ & $11(6.6)$ & $327(8.2)$ & 0.008 & $5.23(1.53-17.87)$ \\
\hline \multirow{7}{*}{ Contraception method } & No & $28(17)$ & $455(11.3)$ & - & 1 \\
\hline & Condom & $11(6.7)$ & $449(11.1)$ & 0.01 & $0.39(0.19-0.80)$ \\
\hline & OCP & $43(26.1)$ & $977(24.2)$ & 0.17 & $0.71(0.439-1.16)$ \\
\hline & IUD & $29(17.6)$ & $762(18.9)$ & 0.32 & $0.73(0.39-1.35)$ \\
\hline & Withdrawal & $8(4.8)$ & $327(8.1)$ & 0.07 & $0.61(0.36-1.05)$ \\
\hline & Progestin & $17(10.3)$ & $377(9.4)$ & 0.02 & $0.39(0.17-0.88)$ \\
\hline & Surgery & $29(17.6)$ & $683(16.9)$ & 0.17 & $0.69(0.4-1.17)$ \\
\hline \multirow{4}{*}{ Parity } & No & $2(1.2)$ & $135(3.3)$ & - & 1 \\
\hline & 1 & $12(7.1)$ & $926(22.8)$ & 0.86 & $0.87(0.19-3.95)$ \\
\hline & $2-4$ & $93(55.4)$ & $2304(56.7)$ & 0.16 & $2.72(0.66-1.17)$ \\
\hline & $\geq 5$ & $61(36.3)$ & $699(17.2)$ & 0.01 & $5.89(1.42-24.38)$ \\
\hline \multirow{4}{*}{ Type of delivery } & No & $1(0.6)$ & $139(3.4)$ & - & 1 \\
\hline & NVD & $18(10.7)$ & $919(22.6)$ & 0.33 & $2.72(0.36-20.55)$ \\
\hline & $\mathrm{CS}$ & $136(81)$ & $2740(67.5)$ & 0.05 & $6.89(0.95-49.69)$ \\
\hline & NVD-CS & $13(7.7)$ & $260(6.4)$ & 0.06 & $6.95(0.90-53.68)$ \\
\hline \multirow{3}{*}{ Organism } & $\mathrm{NO}$ & $107(62.9)$ & $3272(80.6)$ & - & 1 \\
\hline & HPV & $26(15.3)$ & $3(0.1)$ & 0.0001 & $265(78-889)$ \\
\hline & Other organism & $37(21.8)$ & 784(19.3) & 0.06 & $1.44(0.98-2.11)$ \\
\hline \multirow{2}{*}{ Breast feeding } & Yes & $16(9.5)$ & $594(14.6)$ & \multirow{2}{*}{0.06} & 1 \\
\hline & No & $153(90.5)$ & $3464(85.4)$ & & $1.64(0.97-2.76)$ \\
\hline \multirow{2}{*}{ Menopause } & Yes & $35(21.6)$ & $375(9.4)$ & \multirow{2}{*}{0.0001} & 1 \\
\hline & No & $127(78.4)$ & $3628(90.6)$ & & $0.037(0.25-0.55)$ \\
\hline \multirow{2}{*}{ Pap smear screening history } & Yes & $47(28)$ & $1058(26.2)$ & \multirow{2}{*}{0.61} & 1 \\
\hline & No & $121(72)$ & $2979(73.8)$ & & $0.91(0.64-1.29)$ \\
\hline \multirow{2}{*}{ History of abnormal pap result } & Yes & $44(93.6)$ & $1023(97.5)$ & \multirow{2}{*}{0.12} & 1 \\
\hline & No & $3(6.4)$ & $26(2.5)$ & & $2.68(0.78-9.2)$ \\
\hline \multirow{2}{*}{ Awareness of pap smear test } & Yes & $85(51.8)$ & $2458(61.7)$ & \multirow{2}{*}{0.011} & 1 \\
\hline & No & $79(48.2)$ & $1526(38.3)$ & & $1.49(1.09-2.04)$ \\
\hline
\end{tabular}


Table 4. Multivariate Models Results of Abnormal Papl Smear Results

\begin{tabular}{|c|c|c|c|}
\hline \multicolumn{2}{|c|}{ Variable } & Odds (CI 95\%) & P value \\
\hline \multirow{4}{*}{ Age(year) } & $15-25$ & 1 & - \\
\cline { 2 - 4 } & $26-35$ & $2.85(0.88-9.32)$ & 0.031 \\
\cline { 2 - 4 } & $36-45$ & $7.06(1.97-25.29)$ & 0.003 \\
\cline { 2 - 4 } & $46-55$ & $6.65(1.58-27.83)$ & 0.009 \\
\cline { 2 - 4 } & $56-65$ & $6.17(0.99-38.36)$ & 0.051 \\
\hline \multirow{2}{*}{$\begin{array}{c}\text { Awareness } \\
\text { of pap smear } \\
\text { test }\end{array}$} & Yes & 1 & - \\
\cline { 2 - 4 } & No & $1.6(1.1-2.34)$ & 0.014 \\
\hline \multirow{3}{*}{\begin{tabular}{c} 
Organism \\
\cline { 2 - 4 }
\end{tabular}} & No & 1 & - \\
\cline { 2 - 4 } & HPV & $482.4(108.4-2145)$ & 0.0001 \\
\hline & Other & $1.4(0.924-2.14)$ & 0.11 \\
\hline
\end{tabular}

\section{Results}

The most of participants were between 26 and 35 years and housewives, and had elementary to secondary education. Age at first marriage, in the majority of participants, was 16-20 years with the mean age of 19.2 \pm 5.4 . the marriages lasted less than 15 years. Most of the participants had a history of 2-4 pregnancies, and experienced natural childbirth. During sampling, the subjects were non-lactating and premenopausal. In addition, $38.7 \%$ of the subjects had not heard about the Pap smear test and $73.7 \%$ of them had no previous history of Pap smear. At the time of sampling, 24.3\% of the subjects had used combined hormonal contraceptive methods (Table 1).

Of the samples, 99.6\% (4237 cases) had a good quality. More than $96.5 \%$ (4103 cases) of samples had endocervical cells. The most common cause of elimination of samples was being covered with secretions. Moreover, $89.38 \%$ of the study population had inflammatory changes (mild, moderate, and severe). The incidence of abnormal changes in cervical intraepithelial cells was $3.97 \%$ and the incidence of these changes in endocervical cells was $0.07 \%$. The highest percentage of abnormal changes $(1.9 \%)$ in cervical epithelial cells was related to atypical squamous cells of undetermined significance (ASCUS) (Table 2). A statistically significant association was observed between the variables of age $(\mathrm{P}<0.001)$, age at first marriage $(\mathrm{P}<0.010)$, education $(\mathrm{P}<0.001)$, multiparity $(\mathrm{P}<0.001)$, infection by microorganisms $(\mathrm{P}<0.001)$, menopause $(\mathrm{P}<0.0001)$, and lack of awareness about Pap smear $(\mathrm{P}<0.010)$ and abnormal cervical smear results. This relationship was not significant regarding breastfeeding, use of contraceptive methods, and Pap smear history and result $(\mathrm{P}>0.050)$. The logistic regression model showed that age, presence of microorganisms, lack of awareness about Pap smear, and HPV were the factors related to abnormal Pap smear results in women living in Zanjan.

\section{Discussion}

Cervical cancer is one of the most common causes of death among women in developing countries. Therefore, early detection of this disease in the precancerous stage based on Pap smear test screening is utmost importance especially in Muslim country. The present study investigated the prevalence of abnormal Pap smear results, such as infections, and inflammatory, precancerous changes and factors associated with these changes. The incidence of inflammatory changes in this study was $89.3 \%$, this figure was $77.2 \%$ in the study by Barouti et al (Barouti, Farzaneh, Sene, Tajik, and Jafari, 2013) in Tehran. This showed the high prevalence of these changes in the present study. Furthermore, cervical dysplastic changes were observed in 173 cases $(4.04 \%)$. Of which, 81 cases $(47.2 \%)$ were related to ASCUS, 40 cases $(23 \%)$ to ASCH, 43 cases (24.7\%) to LSIL, and 6 cases $(3.46 \%)$ to HSIL, and 3 cases $(1.73 \%$ ) had AGUS changes. Many studies have been conducted in Iran and some Muslim countries , the prevalence of cervical dysplasia in the 6024 Pap smear samples examined was $1.02 \%$ in Tabriz, (Jafari Shobeiri, 2007) in reviewing of 13,315 Pap smear samples in Tehran, found a $1.8 \%$ incidence of neoplastic changes. Among which, 58.18\% were ASCUS, $17.73 \%$ LSIL, $10.75 \%$ HSIL, $1.26 \%$ AGUS, and $0.2 \%$ were reported as cervical carcinoma(Afrakhteh, Khodakarami, Moradi, Alavi, and Shirazi, 2007). In a similar study on Turkish women, was $2.8 \%$ (including $1.9 \%$ ASCUS, $0.1 \%$ ASCH, $0.5 \%$ LSIL, $0.1 \%$ HSIL, and 0.2\% AGUS). (Atilgan et al., 2012) In addition, in the study by Mehmetoglu et al., the incidence of cervical dysplasia was $1.2 \%$, (Mehmetoglu et al., 2010) and in the study by Ghaith et al. this figure was $3.3 \%$ (Al Eyd and Shaik, 2012). These results were not consistent with the results of the present study So that, the prevalence of intraepithelial neoplastic lesions in the present study was higher than that in the above mentioned studies, and lower than that of the study by Abdoulah (5\%) and Al-Kadri, Hanan., et al (4.3\%) in Saudi Arabia, (Abdullah, 2006; Al-Kadri, Kamal, Bamuhair, Omair, and Bamefleh, 2015) Banik in Turkey (8.18\%)(Banik, Bhattacharjee, Ahamad, and Rahman, 2011) Respectively . The differences in the prevalence of inflammatory changes and cervical dysplasia can be the result of social and cultural differences, age, incidence of related infections, and the presence or absence of cervical cancer screening programs in different societies. Due to the high incidence of dysplasia in this study, compared with similar studies in other provinces of Iran and some neighboring Muslim countries, the importance of screening programs is felt more than ever. In this study, ASCUS lesions accounted for the largest percentage of abnormal cervical screening results, and its incidence was similar to some other studies. (Afrakhteh et al., 2007; Atilgan et al., 2012). It should be noted that at this stage the cervical dysplastic lesions are easily detected and treated and in the absence of appropriate treatment they have the ability to progress to cervical cancer.

In this study, the variables of age, lack of awareness about Pap smear, HPV, and microorganisms were factors associated with dysplastic changes of cervical smear. These results were consistent with previous studies in this area (Akyuz, Guvenc, Yavan, Cetinturk, and Kok, 2006; El-All, Refaat, and Dandash, 2007; Jafari Shobeiri, 2007; Mehmetoglu et al., 2010). The highest prevalence 
of dysplastic changes in this study was observed in the age group of 36-45 years. In this regard, the odds ratio increased with increasing age up to the age group of 4655 years. In the study by Karimi Zarchi investigating the risk factors for cervical cancer, the mean age of patients with cervical cancer was 53.6 years (Zarchi et al., 2010) and the similar studies was reported in women of 45-50 years of age. (Kritpetcharat, Wutichouy, Sirijaichingkul, and Kritpetcharat, 2012; Stanley, 2012) in this study, HPV infection was associated with abnormal Pap smear results. In the study by Ghaffari et al. (2006) HPV was reported in $60 \%$ of the samples with dysplasia and only in $13 \%$ of the samples without dysplastic lesions (Ghaffari et al., 2006). In their study, a strong and significant association was observed between HPV infection, cell dysplasia, and cervical cancer.

In the present study, $38.7 \%$ of the subjects had no information about Pap smear and this was associated with abnormal results. In the study of Mehmetoglu et al in Turkey, $90.7 \%$ of the participants had no knowledge of Pap smear tests. (Mehmetoglu et al., 2010). In the study by Akyuz et al. (2006) only $29.7 \%$ of the subjects had information about the Pap smear test (Akyuz et al., 2006), which was not consistent with the results of the present study. Differences in the level of awareness could be affected by providing information and training in target groups of cervical cancer screening programs. The effective implementation of this program could be a step towards improving the health of women.

Given the prevalence of inflammatory and precancerous changes in this study, compared to other studies performed in Iran and Muslim countries, and the effect of some demographic variables and individual factors on abnormal results, increasing the awareness of women and their families regarding the risk factors for cervical cancer, preventive measures such as screening, and timely treatment of the disease seems necessary. Moreover, the lack of sufficient awareness of women of cervical cancer screening tests and no previous history of Pap smear tests in a significant percentage of the participants in this study emphasizes the necessity of a comprehensive screening program.

\section{Acknowledgements}

This study was founded by a grant from zanjan university of medical sciences, Deputy of research and technology and zanjan provaince general governor. Authors have no conflict of interest

\section{References}

Abdullah LS (2006). Pattern of abnormal Pap smears in developing countries: a report from a large referral hospital in Saudi Arabia using the revised 2001 Bethesda System. Ann Saudi Med, 27, 268-272.

Afrakhteh M, Khodakarami N, Moradi A, et al (2007). A study of 13315 papanicolau smear diagnoses in Shohada Hospital. $J$ Family Reproductive Health, 1, 74-8.

Aggarwal P (2014). Cervical cancer: Can it be prevented? World J Clin Oncol, 5, 775-80.
Akyuz A, Guvenc G, Yavan T, et al (2006). Evaluation of the Pap smear test status of women and of the factors affecting this status. Gulhane Med J, 48, 025-029.

Al-Kadri H M, Kamal M, Bamuhair S S, et al (2015). Prevalence and characteristics of abnormal Papanicolaou smear in Central Saudi Arabia. Saudi Med J, 36, 117.

Al Eyd GJ, Shaik RB (2012). Rate of opportunistic pap smear screening and patterns of epithelial cell abnormalities in pap smears in Ajman, United arab emirates. Sultan Qaboos University Med J, 12, 473.

Arbyn M, Castellsague X, De Sanjose S, et al (2011). Worldwide burden of cervical cancer in 2008. Ann Oncol, 22, 2675-86.

Atilgan R, Celik A, Boztosun A, et al (2012). Evaluation of cervical cytological abnormalities in Turkish population. Indian J Pathol Microbiol, 55, 52.

Banik U, Bhattacharjee P, Ahamad S U, et al (2011). Pattern of epithelial cell abnormality in Pap smear: Aclinicopathological and demographic correlation. Cytojournal, 8, 8 .

Barouti E, Farzaneh F, Sene AA, et al (2013). The Pathogenic Microorganisms in papanicolaou vaginal smears and correlation with inflammation. J Family Reproduct Health, $7,23$.

Benard VB,Thomas CC, King J, et al (2014). Vital Signs: Cervical Cancer Incidence, Mortality, and Screening-United States, 2007-2012. MMWR. Morbidi Mortal Weekly Report, 63, 1004-9.

El-All H, Refaat A, Dandash K (2007). Prevalence of cervical neoplastic lesions and human papilloma virus infection in egypt: national cervical cancer screening project. Infect Agent Cancer, 2, 12.

Ghaffari S R, Sabokbar T, Mollahajian H, et al (2006). Prevalence of human papillomavirus genotypes in women with normal and abnormal cervical cytology in Iran. Asian Pac J Cancer Prev, 7, 529.

Jafari Shobeiri M (2007). Screening for cervical cancer and precancerous lesions in Tabriz. Med J Islamic Republic Iran, 21, 1-10.

Khorasanizadeh F, Hassanloo J, Khaksar N, et al (2013). Epidemiology of cervical cancer and human papilloma virus infection among Iranian women-Analyses of national data and systematic review of the literature. Gynecologic Oncol, 128, 277-81.

Kritpetcharat O, Wutichouy W, Sirijaichingkul S, et al (2012). Comparison of Pap Smear screening results between Akha hill tribe and urban women in Chiang Rai province, Thailand. Asian Pac J Cancer Prev, 13, 5501-4.

McGraw SL, Ferrante JM (2014). Update on prevention and screening of cervical cancer. World J Clin Oncol, 5, 744-752.

Mehmetoglu H C, Sadikoglu G, Ozcakir A, et al (2010). Pap smear screening in the primary health care setting: A study from Turkey. North Am J Med Sci, 2, 467.

Ncube B, Bey A, Knight J, et al (2015). Factors associated with the uptake of cervical cancer screening among women in portland, Jamaica. $N$ Am J Med Sci, 7, 104-113.

Stanley MA (2012). Genital human papillomavirus infections: current and prospective therapies. J General Virol, 93, 681-91.

Whitaker C J, Stamp E C, Young W, et al (2009). Comparison of the efficacy of the cervex brush and the extended-tip wooden spatula with conventional cytology: A longitudinal study. Cytojournal, 6, 2.

Zarchi MK, Akhavan A, Gholami H, et al (2010). Evaluation of cervical cancer risk-factors in women referred to Yazd-Iran hospitals from 2002 to 2009. Asian Pac J Cancer Prev, 11, 537-8. 